\section{Seasonal affective disorder among general practice} attenders $^{\dagger}$

TONY KENDRICK

In this issue, Eagles et al report that people suffering from seasonal affective disorder (SAD) are heavy users of primary health care services (Eagles et al, 2002, this issue). Nearly $10 \%$ of patients attending practices in Aberdeen screened positive for SAD using the Seasonal Pattern Assessment Questionnaire (SPAQ; Rosenthal et al, 1987), among whom around half of those attending for interview fulfilled DSM-IV (American Psychiatric Association, 1994) criteria for recurrent major depression with seasonal pattern. The patients with SAD had consulted significantly more frequently over a 5-year period, with a variety of symptoms both related and unrelated to $\mathrm{SAD}$, and had received significantly more prescriptions, investigations and referrals than patients found not to fulfil the criteria for SAD.

None of the patients studied had been diagnosed as cases of SAD and only in a very few, judging by their practice records, had the possibility ever been considered. This finding supports that of Michalak $e t$ al (2001), who carried out a similar study in a population sample and found that only one of 25 cases had received a diagnosis of SAD, although over half had been diagnosed with other forms of depression and had been prescribed antidepressants.

As a researcher interested in mental health problems in primary care, I am intrigued by these findings. I want to know how they relate to similar findings in nonseasonal depression, and to consider the implications for further research, especially intervention studies. As a general practitioner I am uncertain about the implications for how I should practise, in particular the implication that maybe we should be screening for SAD in primary care.

\footnotetext{
†See pp. 449-454, this issue.
}

\section{SIMILARITIES BETWEEN SAD AND NON-SEASONAL DEPRESSION}

Eagles and his Aberdeen group point out in their discussion the clear similarities between their findings in SAD and the literature on non-seasonal depression. Depression is common among general practice attenders but often goes undetected, in many cases because patients present with somatic symptoms and coexisting physical illnesses. Patients with depression consult more frequently, receive more prescriptions for physical as well as mental health problems, undergo more physical investigations and receive more non-psychiatric referrals and admissions to hospital. In all these respects, therefore, $\mathrm{SAD}$ does not differ from depression in general.

Seasonal affective disorder has been shown to respond to antidepressants (Lam et al, 1995), and there is still debate about whether SAD represents a distinct variant of affective disorder with a course and prognosis different from other forms of recurrent depression. However, proponents would argue that SAD is worth diagnosing because the potential for intervention is different from that in other forms of depression, given the availability of a cheap, relatively non-invasive, specific treatment - light therapy - which might be more acceptable to patients who do not wish to take antidepressants.

\section{THE NEED FOR MORE RESEARCH}

Light therapy has been found to be acceptable and apparently beneficial in SAD, at least among those sufferers identifying themselves as such and volunteering for treatment in specialist settings (Tam et al, 1995). However, as the Aberdeen group recognises, this efficacy may not extend to patients presenting with other problems in general practice who are found, on screening, to fulfil the criteria for SAD. Their own trial conducted on a relatively small number of their primary care patients with SAD demonstrated no superiority of bright white light over dim red light, with the majority in both groups recovering within 4 weeks (Wileman et al, 2001). They have suggested, however, that dim red light should not be considered as an inactive or inert placebo because it mimics all the non-specific effects of an active treatment, and they have argued that the most appropriate and pragmatic control is 'treatment as usual' (Wileman et al, 2001). A pragmatic trial of light therapy against treatment as usual for patients with SAD identified through screening in primary care would be a logical next step, but I would like to add a third arm with an inert placebo such as a negative ion generator, to look again at the placebo effect in this condition. As well as symptoms of depression, other outcomes of interest would include side-effects, quality of life, social functioning, satisfaction with care received, use of services and costs.

\section{SHOULD WE SCREEN GENER AL PRACTICE PATIENTS FOR SAD?}

There is clearly considerable comorbidity between affective symptoms and physical symptoms among primary care patients, and general practitioners may feel that dealing with the physical symptoms presented to them, and the passage of time, will usually resolve their patients' accompanying psychological distress. The important issue for general practitioners is whether reattribution of symptoms and treatment for depression - and, in this context, specific therapy for SAD found on screening practice attenders - is likely to be more successful in relieving their patients' distress than the strategies they have adopted up until now. More convincing evidence is needed that the cluster of symptoms comprising the syndrome accurately predicts the course of the illness and response to treatment - such evidence is lacking for diagnostic categories in nonseasonal depression when applied to primary care patients (Wright, 1994).

Screening for SAD would not fulfil other criteria considered to be necessary for mounting a screening programme. The 
SPAQ is sensitive but not very specific, and diagnostic interviews would be very expensive. The approach may not be acceptable to many patients because around one-third of people approached decline to complete the SPAQ and, of those screening positive, a significant proportion decline to attend for diagnostic interview (Michalak et al, 2001; Eagles et al, 2002, this issue).

\section{REATTRIBUTION}

However, even if light therapy does prove effective for patients found in primary care to fulfil the criteria for SAD, the reattribution approach is unlikely to be taken up widely. Research has shown that patients found to be positive on screening with the General Health Questionnaire (Goldberg \& Williams, 1991), who attribute their symptoms to physical causes (somatising attributional style) or to non-illness causes (normalising style), are less likely to be labelled as depressed, and therefore treated for depression, than those with a psychologising style (Kessler et al, 1999). Practitioners seem, therefore, to go along with patients' attributions rather than try to reattribute symptoms and persuade patients to accept treatment for depression. There is resistance among general practitioners to the idea that large numbers of the patients attending their practices need treatment for depression, because this is seen to be medicalising human distress (Heath, 1999).

\section{CASE-FINDING}

An alternative to screening is case-finding, looking for SAD among patients attending our practices who can be identified to be at greater risk. The Aberdeen study showed higher consultation rates among patients with SAD, of around six to seven consultations per year. The increased consultation rate may be more significant in the autumn and winter, but also was found to be raised at other times in the year (Andrew et al, 2001 ). Around $25 \%$ of the practice population will consult at such a rate (Neal et al, 1998), suggesting that we would still face

TONY KENDRICK, FRCPsych, Primary Medical Care, Aldermoor Health Centre, Southampton SOI6 5ST, UK. Tel: 0238024 1050; Fax: 0238070 II25; e-mail: arkl@soton.ac.uk

(First received 8 August 200I, final revision 19 December 200I, accepted 19 December 200I)

a considerable challenge if we were to attempt to seek out SAD among all our more frequent attenders, even in a practice with average consultation rates: in deprived areas with high consultation rates and high levels of depression, general practitioners often feel overwhelmed by the notion that they should be looking for more cases of depression (Howe, 1996).

If depression is identified, then there could be advantages in considering SAD as a more specific diagnosis, because light therapy may be more acceptable to some patients than antidepressants. There are frequently atypical symptoms in $\mathrm{SAD}$, such as carbohydrate craving, increased sleep and an afternoon slump in energy, which are thought to indicate a greater likelihood of responding to light therapy (Terman et al, 1996). General practitioners could become more aware of SAD and consider light therapy where appropriate. It is, at the very least, a relatively harmless placebo. The reattribution approach will still hinge, however, on whether our patients will accept the explanation that their physical as well as mental symptoms could be due to $\mathrm{SAD}$, and whether they will accept light therapy. Eagles et al's work suggests that at least a proportion of them will accept such an approach. I suppose we could sell it as the nearest we can offer them to a winter holiday in the sun.

\section{DECLARATION OF INTEREST}

None.

\section{REFERENCES}

American Psychiatric Association (1994) Diagnostic and Statistical Manual of Mental Disorders (4th edn) (DSM-IV). Washington, DC: APA.

Andrew, J. E., Wileman, S. M., Howie, F. L., et al (2001) A comparison of consultation rates in primary care attenders with and without seasonal affective disorder. Journal of Affective Disorders, 62, 199-205.
Eagles, J. M., Howie, F. L., Cameron, I. M., et al (2002) Use of healthcare services in seasonal affective disorder. British Journal of Psychiatry, $\mathbf{1 8 0}$ 449-454.

Goldberg, D. \& Williams, P. (198I) A User's Guide to the General Health Questionnaire.Windsor: NFER-Nelson.

Heath, I. (1999) Commentary: There must be limits to the medicalisation of human distress. BMJ, $\mathbf{3 1 8}$, 439-440.

Howe, A. (1996) 'I know what to do, but it's not possible to do it' - general practitioners' perceptions of their ability to detect psychological distress. Family Practice, 13, 127-132.

Kessler, D., Lloyd, K., Lewis, G., et al (1999) Crosssectional study of symptom attribution and recognition of depression and anxiety in primary care. BMJ, 318, 436-439.

Lam, R. W., Gorman, C. P., Michalon, M., et al (1995) Multicenter, placebo-controlled study of fluoxetine in seasonal affective disorder. American Journal of Psychiatry, 152, 1765-1770

Michalak, E. E., Wilkinson, C., Dowrick, C., et a (200I) Seasonal affective disorder: prevalence, detection and current treatment in North Wales. British Journal of Psychiatry, 179, 31-34

Neal, R. D., Heywood, P. L., Morley, S., et al (1998) Frequency of patients' consulting in general practice and workload generated by frequent attenders: comparisons between practices. British Journal of General Practice, 48, 895-898.

Rosenthal, N. E., Genhart, M., Sack, D. A., et a (1987) Seasonal affective disorder: relevance for treatment and research of bulimia. In Psychobiology of Bulimia (eds J. I. Hudson \& H. G. Pope), pp. 205-208. Washington, DC: American Psychiatric Association.

Tam, E. W., Lam, R. W. \& Levitt, A. J. (1995)

Treatment of seasonal affective disorder: a review. Canadian Journal of Psychiatry, 40, 457-466.

Terman, M., Amira, L., Terman, J. S., et al (1996) Predictors of response and non-response to light treatment for winter depression. American journal of Psychiatry, 153, 1423-1429.

Wileman, S. M., Eagles, J. M., Andrew, J. E., et al (200I) Light therapy for seasonal affective disorder in primary care. Randomised controlled trial. British Journal of Psychiatry, 178, 31I-316.

Wright, A. F. (1994) Should general practitioners be testing for depression? British Journal of General Practice, 44, 132-135. 